\title{
Puberty due to Ectopic HCG Production in a Girl with Suprasellar Ectopic Pinealoma Associated with Panhypopituitarism
}

\author{
Reiko DEMURA, Osami KUBO*, KoIChi KITAMURA*, KAzUKo JIBIKI, \\ Emi ODAGIRI, Hiroshi DEMURA and KazUo SHIZUME
}

Department of Internal Medicine and Neurosurgery*, Tokyo Women's Medical College, 10-Kawadacho, Ichigaya, Shinjuku-ku, Tokyo 162

\begin{abstract}
A 13.5-year-old girl who developed puberty due to HCG production by suprasellar ectopic pinealoma was reported. This girl appeared to be in a state of precocious puberty at the age of 5 when ectopic pinealoma was first diagnosed. Her breasts started to develop at 13 years of age in spite of hypopituitarism. Plasma LH was found to increase for several months and gave rise to suspicion of the recurrence of the tumor, which was confirmed by the detection of HCG in plasma and CSF. Precocious puberty or puberty can be a characteristic endocrinological manifestation of an HCG producing tumor not only in boys but also in girls. The measurement of plasma HCG (or LH) can be a useful tumor marker in following the clinical course of an HCG producing tumor.
\end{abstract}

\section{Case Report}

We have reported a 5-year-old girl who showed signs of precocious puberty due to an HCG producing suprasellar ectopic pinealoma (Demura et al., 1976). Secondary sexual characteristics appeared in the same girl at the age of 13.5 years in spite of hypopituitarism, and plasma $\mathrm{LH}$ started to increase. This led us to suspect a recurrence of the tumor, and this was confirmed by further endocrinological and neuroradiological studies and the patient was treated successfully.

Received December 14, 1983
K. U., a 13.5-year-old girl has been followed in our OPD since the age of 5 years when she was diagnosed to have an HCG producing suprasellar ectopic pinealoma. Partial extirpation of the tumor and radiation therapy were done successfully. Histological examination revealed a typical two cell pattern pinealoma. Soon after treatment, plasma $\mathrm{HCG}$ came down to an undetectable level and her mammary development subsided and she became hypopituitaristic. She had been doing well with hydrocortisone, thyroid hormone, growth hormone and DDAVP replacement therapy. Her breasts started to develop again at 13 years of age and reached Tanner stage 3 in a few months. At the same time, her 
plasma LH levels were getting higher and higher. Recurrence of the HCG producing tumor was suspected and further studies were performed. Her height was $140.2 \mathrm{~cm}$ and weight was $31 \mathrm{~kg}$. No axillary or pubic hair was noted and she has never had vaginal bleeding.

\section{Methods}

Plasma LH and FSH were measured with radioimmunoassay (RIA) kits made by Eiken I.C.L., Tokyo, Japan. Plasma HCG and HCG$\beta$ were measured with RIA kits made by CIS, France. Using these kits, LH crossreacted 100 $\%$ with HCG, HCG crossreacted $0.66 \%$ with LH and $100 \%$ with HCG- $\beta$. FSH crossreacted $2.95 \%$ with LH and $0.51 \%$ with HCG. HCG$\beta$ crossreacted $0.3 \%$ with $\mathrm{LH}$ and $8 \%$ with HCG. An LH-RH, TRH test was performed by simultaneously i.v. injecting $500 \mu \mathrm{g}$ of TRH and $100 \mu \mathrm{g}$ of LH-RH.

\section{Results}

Changes in plasma LH and FSH levels are shown in Fig. 1. Plasma LH levels started to increase over the past several months with a slight elevation in plasma FSH levels, although both of these had remained suppressed for 8 years since the first treatment. Responses of plasma LH, FSH, HCG, HCG$\beta$ and prolactin to $\mathrm{LH}-\mathrm{RH}, \mathrm{TRH}$ are shown in Fig. 2. LH and FSH remained unchanged in spite of elevated basal levels. HCG was found abnormally high but did not respond to LH-RH. HCG- $\beta$ was not detected in plasma throughout the course of treatment. Basal levels of plasma thyroid hormone and cortisol were in the normal range in the condition of replacement of thyroid and adrenal hormones. Plasma estradiol and progesterone gradually increased along with the elevation of plasma LH levels (Fig. 3). Plasma CEA and $\alpha$-fetoprotein were in the normal range. Her linear growth curve and bone age are shown in Fig. 4. A Neuroradiological examination revealed abnormal calcification in the suprasellar and pineal regions. A CSF smear revealed a few atypical lymphocytes.

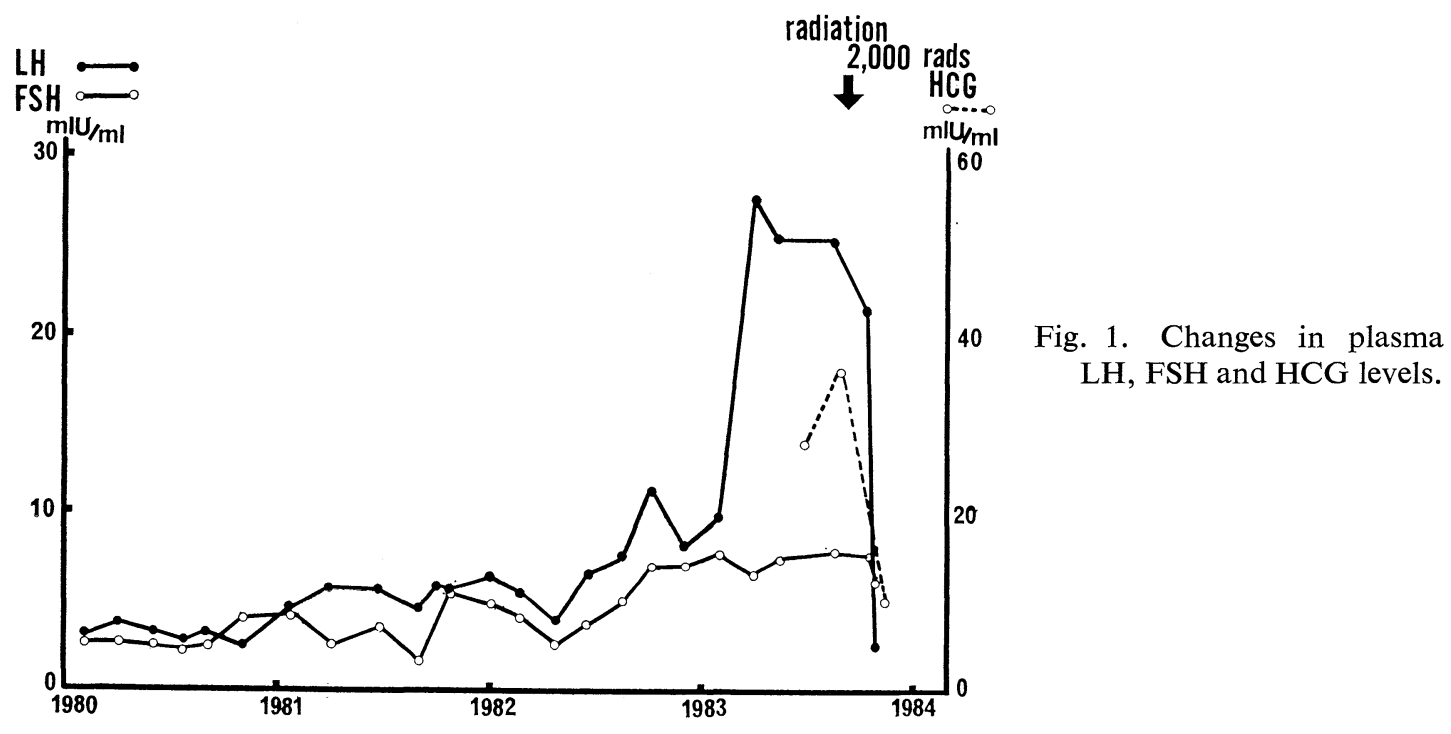




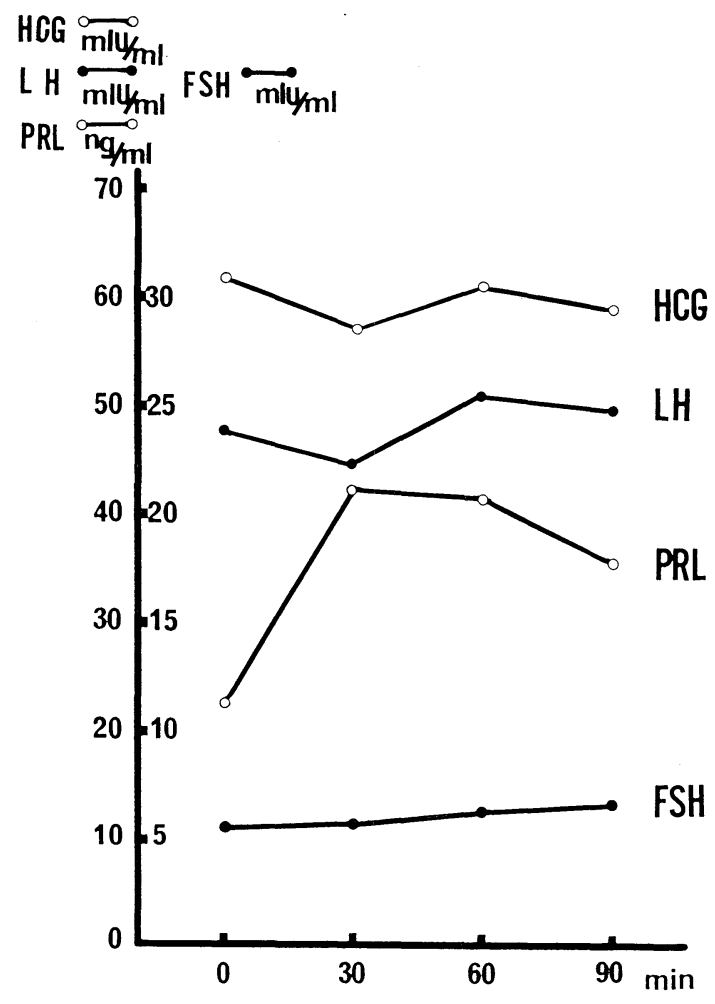

Fig. 2. LH-RH, TRH test.
A high level of HCG, ten times as high as that in plasma, was found in CSF (Fig. 5). External radiation with 2,000 rads resulted in a rapid fall in plasma LH, FSH and HCG (Fig. 1) and HCG in CSF (Fig. 5) levels. Breast development subsided to Tanner stage 2 after 2 months of therapy (Fig. 6).

\section{Discussion}

Clinical manifestations in this girl can be defined as a secondary sexual characteristics because her plasma estrogen and progesterone increased concomitantly with her breast development, though she has not had vaginal bleeding or pubic hair yet. Acceleration in linear growth and bone age were also not observed. From her past history and laboratory findings, it is evident that her symptoms were secondary to $\mathrm{HCG}$ production by ectopic pinealoma.

Precocious puberty is known as a characteristic endoclinological manifestation associated with pinealoma or ectopic pinealoma in boys, but not in girls. We have already discussed a different occurence of precocious puberty in both sexes (Demura et al., 1976). It

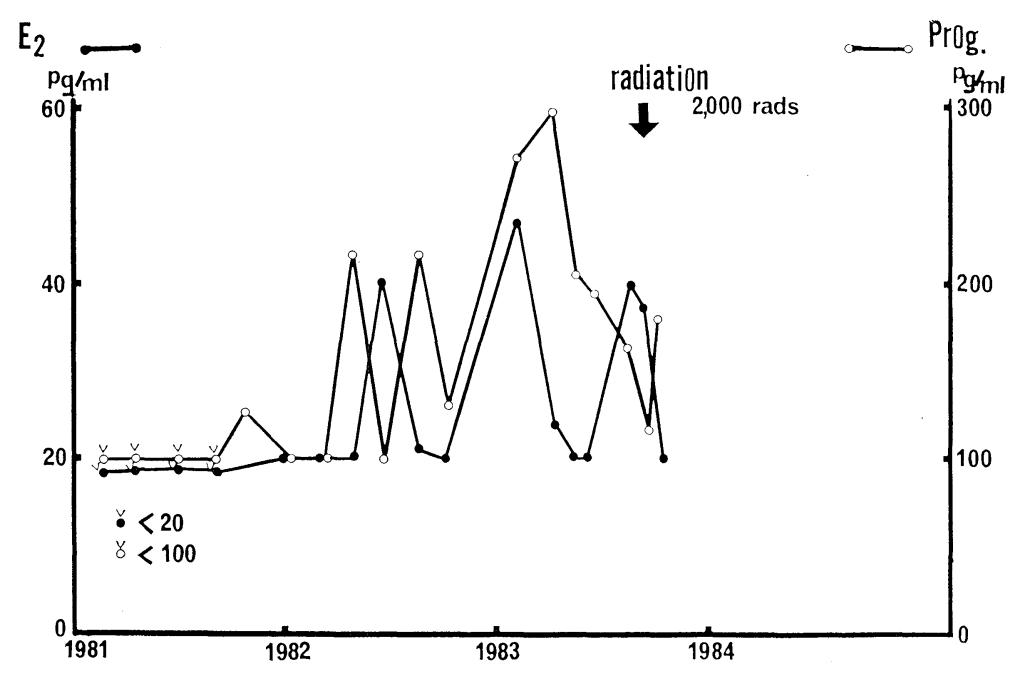

Fig. 3. Changes in plasma estradiol and progesterone levels. 


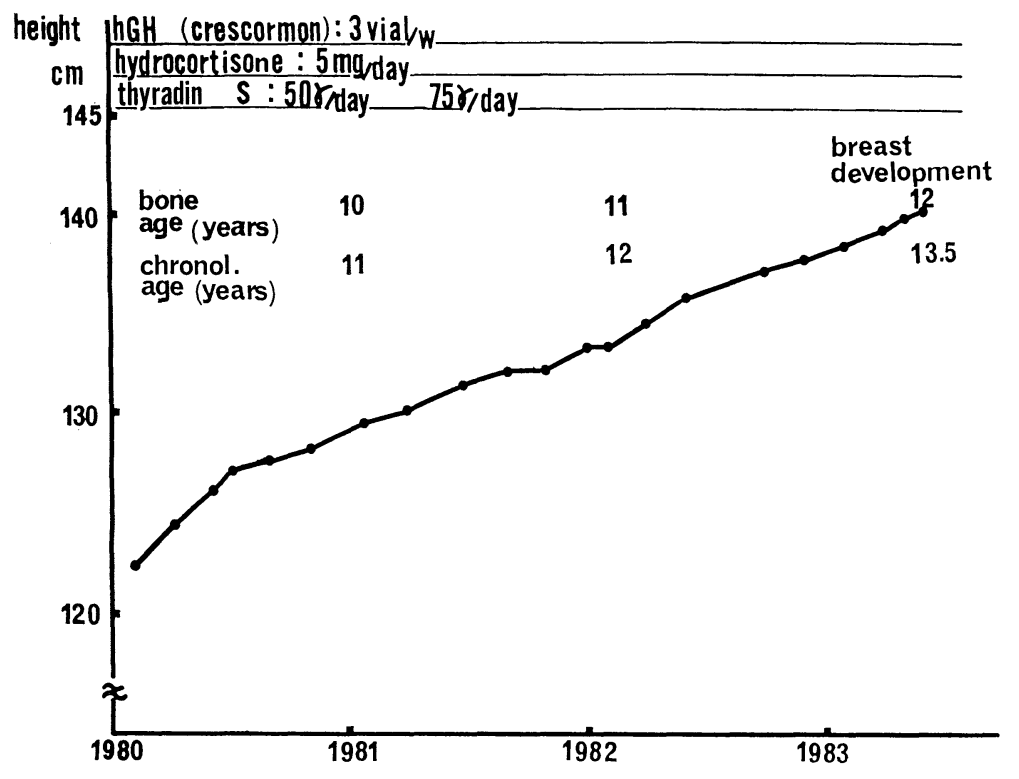

Fig. 4. Linear growth curve.

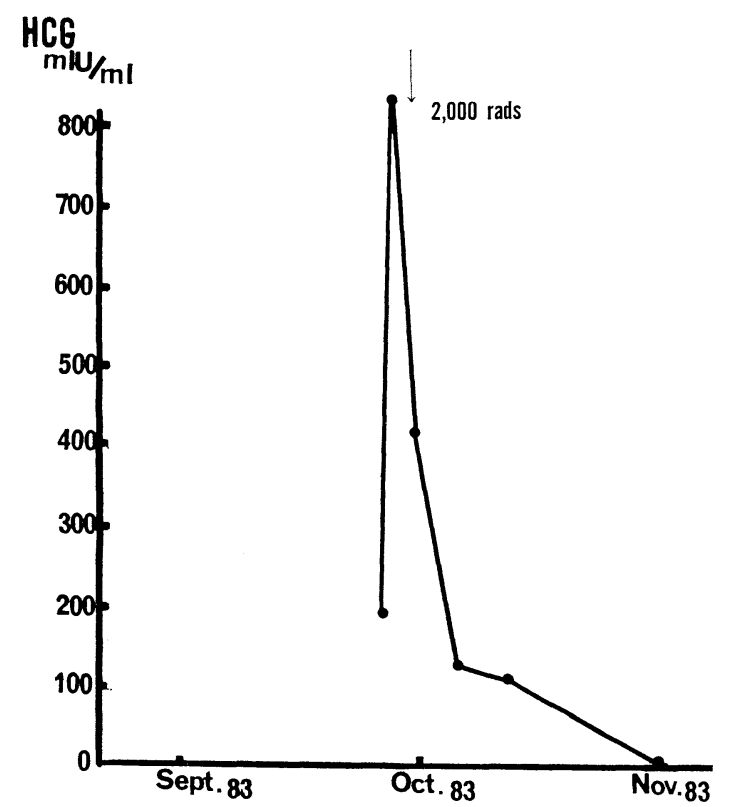

Fig. 5. Changes in HCG level in CSF. is generally accepted that precocious puberty associated with pinealoma is due to ectopic HCG production from the tumor. The most probable explanation for a sexual difference in the occurrence is that testosterone secretion from testis can be induced by $\mathrm{HCG}$ only, but ovarian estrogen secretion can not be stimulated by HCG without the coexistence of FSH (Ross et al., 1981). Low or undetectable levels of plasma FSH have been reported in most of the subjects with $\mathrm{HCG}$ producing tumors (Reiter et al., 1972; Reiter et al., 1973). This girl had normal or only slightly reduced plasma FSH levels throughout her clinical course.

Though she had the signs and symptoms of anterior and posterior pituitary insufficiencies, her plasma prolactin, both basal and in response to TRH, were kept normal. Likewise, her pituitary FSH secretion might be the minimum reserve necessary to stimulate ovarian steroidgenesis along with a fairly large amount of HCG. A slight rise in FSH levels with a steep elevation in the plasma LH and/or HCG level can be explained by a crossreaction of $\mathrm{HCG}$ with FSH. 


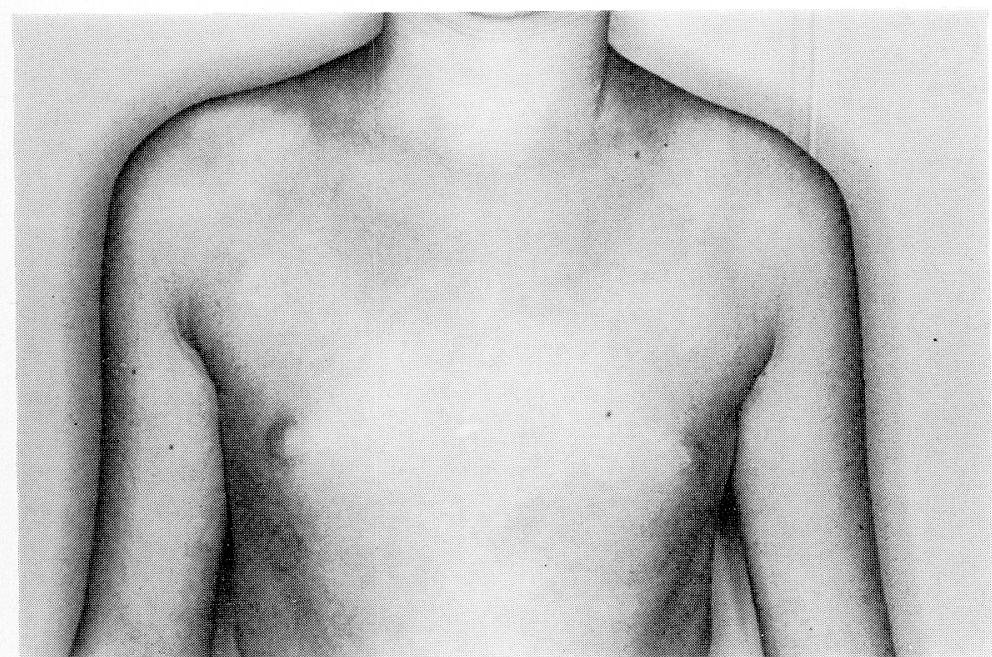

Fig. 6. Breast development. (after radiation)

The elevation in plasma immunoreactive LH with breast development gave rise to suspicion of a recurrence of the HCG producing tumor and detection of $\mathrm{HCG}$ in plasma and/or CSF confirmed the diagnosis. The serial measurement of plasma HCG was a useful marker in following the clinical course and determining the response to treatment (Allen et al., 1979; Jordan et al., 1980), and that was the case with this girl.

\section{Acknowledgements}

This study was partly supported by a research grant for "Specific Disease" from the Japanese Ministry of Health and Welfare and by a research grant from the Japanese Ministry of Education.

\section{References}

Allen, J. C., J. Nisselbaum, F. Epstein, G. Rosen and M. K. Schwartz (1979). Alphafetoprotein and human chorionic gonadotropin determination in cerebrospinal fluid. J. Neurosurg. 51, 368-374.

Demura, R., H. Demura, K. Shizume, O. Kubo and K. Kitamura (1976). A female case of HCG producing ectopic pinealoma associated with precocious puberty. Endocr. Jap. 23,
215-219.

Jordan, R. M., J. W. Kendall, M. McClung and H. Kammer (1980). Concentration of human chorionic gonadotropin in the cerebrospinal fluid of patients with germinal cell hypothalamic tumors. Pediatrics 65, 121-124.

Reiter, E. O., G. D. Braunstein, S. M. Hamwood and H. E. Kulin (1973). Suppressed folliclestimulating hormone (FSH) in women with gestational trophoblastic neoplasms. J. Clin. Endocr. 36, 697-701.

Reiter, E. O., H. E. Kulin and D. L. Loriaux (1972). FSH suppression during short term hCG administration: A gonadally mediated process. J. Clin. Endocr. 34, 1080-1084.

Ross, G.T., R. T. Wandewiele and A.G. Frantz (1981). Textbook of Endocrinology. 6th ed. (edited by R. H. Williams). W. B. Saunders Co., Philadelphia, London and Toronto, p. 379 (1981). 